ARTICLE

DOI: $10.1038 / \mathrm{s} 41467-018-04885-3$

\title{
Formal enantioconvergent substitution of alkyl halides via catalytic asymmetric photoredox radical coupling
}

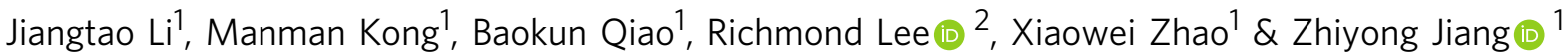

Classic nucleophilic substitution reactions $\left(\mathrm{S}_{N} 1\right.$ and $\left.\mathrm{S}_{N} 2\right)$ are not generally amenable to the enantioselective variants that use simple and racemic alkyl halide electrophiles. The merging of transition metal catalysis and radical chemistry with organometallic nucleophiles is a versatile method for addressing this limitation. Here, we report that visible light-driven catalytic asymmetric photoredox radical coupling can act as a complementary and generic strategy for the enantioconvergent formal substitution of alkyl haldies with readily available and bench-stable organic molecules. Single-electron reductive debrominations of racemic $\alpha$-bromoketones generate achiral alkyl radicals that can participate in asymmetric $\mathrm{C}_{\mathrm{sp} 3}-\mathrm{C}_{\mathrm{sp} 3}$ bonds forming cross-coupling reactions with $\alpha$-amino radicals derived from $N$-aryl amino acids. A wide range of valuable enantiomerically pure $\beta^{2}$ - and $\beta^{2,2}$-amino ketones were obtained in satisfactory yields with good-to-excellent enantioselectivities by using chiral phosphoric acid catalysts to control the stereochemistry and chemoselectivity. Fluoro-heteroquaternary and full-carbon quaternary stereocenters that are challenging to prepare were successfully constructed.

\footnotetext{
${ }^{1}$ Key Laboratory of Natural Medicine and Immuno-Engineering of Henan Province, Henan University, Kaifeng, Henan 475004, China. ${ }^{2}$ Singapore University of Technology and Design, Singapore 487372, Singapore. These authors contributed equally: Jiangtao Li, Manman Kong, Baokun Qiao. Correspondence and requests for materials should be addressed to Z.J. (email: chmjzy@henu.edu.cn)
} 
T he nucleophilic substitution of alkyl halides is a fundamental chemical transformation for precisely delivering molecular fragments to $s p^{3}$-hybridized carbon atoms using halide $(\mathrm{X})$ as a directing group ${ }^{1,2} . \mathrm{S}_{\mathrm{N}} 1$ and $\mathrm{S}_{\mathrm{N}} 2$ reactions are two classic pathways, and they are ubiquitous in organic synthesis. However, the enantioselective version of the $S_{\mathrm{N}} 1$ approach for forming a stereogenic center at the carbon undergoing substitution by a simple alkyl halide, for which no special structural requirement for the removal of $\mathrm{X}$ is designated ${ }^{3-5}$, remains as an unsolved problem due to the reaction mechanism. Meanwhile, the $S_{\mathrm{N}} 2$ reaction is stereospecific for which the generation of chiral products typically requires the utilization of the enantioenriched secondary alkyl halides. In this regard, Fu et al. made a major breakthrough by merging transition metal-catalyzed cross-coupling techniques with radical chemistry (Fig. 1a) ${ }^{6}$. In a bimetallic protocol such as this ${ }^{7}$, achiral alkyl radicals are generated from both racemic alkyl halide reactants through innersphere single-electron transfer (SET) with a chiral transition metal catalyst $\left(\mathrm{Mcat}^{*}\right)$. After transmetalation of the generated $\mathrm{Mcat}^{*} \mathrm{X}$ species with organometallic nucleophiles (NuM) and oxidative addition of the alkyl radical, the alkylmetal-Nu complex, which is produced as a single stereoisomer, undergoes reductive elimination to afford enantioconvergent substitution products. Thus far, this catalytic system has inspired the development of numerous chemical transformations with various NuM species ${ }^{8-10}$. Recently, Fu extended this protocol to nonmetallic secondary amine nucleophiles, where SET between a photosensitive metal-nucleophile complex and an alkyl halide

a

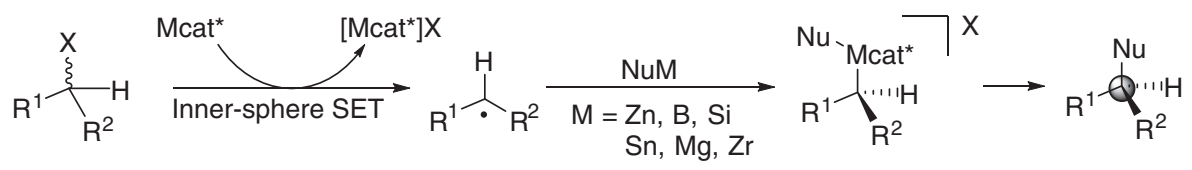

Racemic

Single stereoisomer enantioconvergent

b
$\mathrm{R}^{1}{\stackrel{\mathrm{R}}{\mathrm{\xi}} \mathrm{R}^{3}}^{3}$

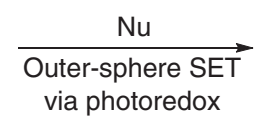
$\mathrm{R}^{1} \overbrace{\mathrm{R}^{2}}^{\mathrm{R}^{3}}+\mathrm{Nu}$

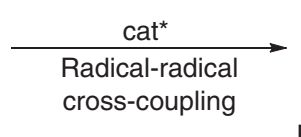
$\mathrm{R}^{1} \oint_{\mathrm{R}^{2}}^{\mathrm{Nu}}$
Racemic
via photoredox
Enantioconvergent

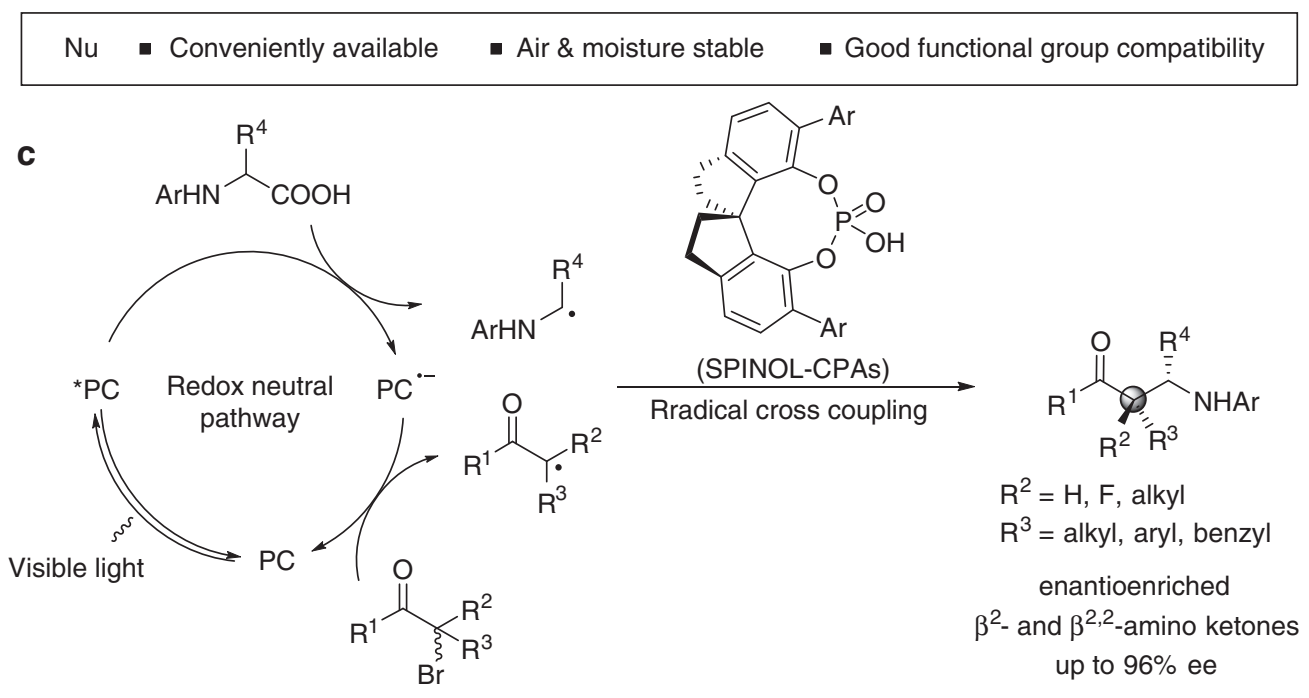

Fig. 1 Strategies for catalytic asymmetric radical-based substitution reactions of simple alkyl halides. a Bimetallic protocol (known). b Radical coupling under visible light-induced photoredox catalysis for enantioconvergent substitution of alkyl halides (design profile). c A dual-catalysis approach to enantioselective radical coupling of $\mathrm{N}$-aryl amino acids to $\alpha$-bromoketones irradiated by visible light (this work). X halide. PC, photoredox catalyst. SPINOL$\mathrm{CPAs}=1,1^{\prime}$-spirobiindane-7,7'-diol (SPINOL)-based spirocyclic chiral phosphoric acids. With the recent rapid development of the field of visible lightmediated photoredox catalysis, this strategy has been seen as a powerful tool for achieving radical-based transformations ${ }^{36,37}$. This catalysis platform has found considerable success in outer-sphere SET oxidations of a wide array of readily available and bench-stable organic molecules as it provides diverse radical species and shows high functional group tolerance. Meanwhile, reductive dehalogenations of alkyl halides via electron transfer-fragmentation processes allows the generation of alkyl radicals ${ }^{33,34}$. In conjunction with our studies 19,20 on the development of enantioselective, dual-catalysis photoredox reactions ${ }^{38-41}$, we speculated that radical coupling reactions 42,43 for connecting two distinct odd-electron partners using an extrinsic stereocontrol factor $44-46$ would provide a complementary and structurally versatile approach for accessing the enantioconvergent products (b). This method would avoid the limitation of the narrow substrate scope faced by direct $\mathrm{S}_{\mathrm{H}} 2$-based radical transformations ${ }^{47}$, where stereoselectivity is also underdeveloped. Notably, the precise and absolute stereocontrol in a reaction with such a low-energy barrier and rapid bond-forming process is a formidable challenge, especially when building an uncommon full-carbon quaternary stereocenter. Here, we demonstrate a generic radical recombination strategy for the enantioselective aminoalkylation of $\alpha$-bromoketones for modular $\mathrm{C}_{\mathrm{sp} 3}-\mathrm{C}_{\mathrm{sp} 3}$ bond formation (c). SPINOL-based spirocyclic chiral phosphoric acid (SPINOL-CPA) catalysts were used to control the chemoselectivity and stereoselectivity of the redox-neutral radical coupling between $\alpha$ bromoketones and $N$-aryl amino acids. Both secondary $\alpha$-bromoketones and tertiary ( $\alpha$-fluoro)- $\alpha$-bromoketones were compatible with this $\alpha$-aminoalkylsubstitution reaction, leading to valuable chiral $\beta^{2}$ - and $\beta^{2,2}$-amino ketones with high enantioselectivities 


\section{Table 1 Optimization of reaction conditions}

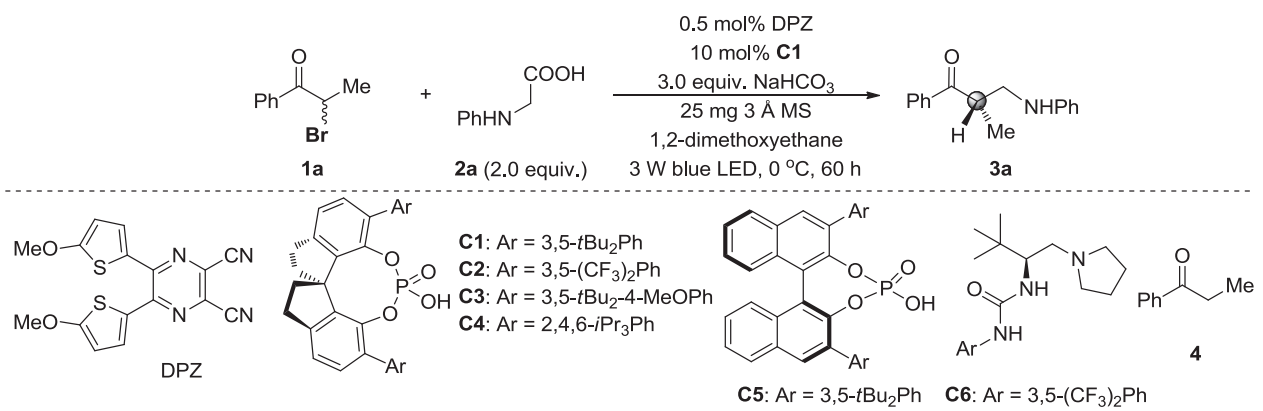

\begin{tabular}{llll}
\hline Entry & Variation from the standard conditions & Yield (\%) $^{\mathbf{a}}$ & ee (\%) \\
\hline 1 & None & 79 & 95 \\
2 & C2 instead of C1 & 77 & 87 \\
3 & C3 instead of C1 & 72 & 94 \\
4 & C4 instead of C1 & 69 & 72 \\
5 & C5 instead of C1 & 70 & 45 \\
6 & C6 instead of C1 & 28 & 0 \\
7 & No C1 & 30 & - \\
8 & No DPZ & 20 & 94 \\
9 & No light & 0 & - \\
\hline
\end{tabular}

The reaction was performed on a $0.05 \mathrm{mmol}$ scale. Entries $1-7$, the chemical conversion of $\mathbf{1 a}$ was $>95 \%$ determined by crude ${ }^{1} \mathrm{H}$ NMR. Entry 8 , the chemical conversion of $\mathbf{1 a}$ was $23 \%$

aYields were determined from the isolated compound following chromatographic purification

bEnantiomeric excesses were determined by HPLC analysis on a chiral stationary phase

under visible light irradiation is responsible for the production of the alkyl radicals ${ }^{11}$. In this context, the capacity of the radical approach to $\mathrm{C}-\mathrm{X}$ bond fragmentation has garnered substantial recognition for generating reactive species that can participate in asymmetric substitution reactions of simple alkyl halides.

\section{Results}

Reaction optimization. The use of the non-fossil fuel-based $\alpha$ amino acids as starting substrates always represents an attractive method in organic synthesis because of their environmentally benign features. In recent years, the groups of $\mathrm{Das}^{12}$, Tan ${ }^{13}$, MacMillan ${ }^{14-16}$, and Rueping ${ }^{17}$ successively reported the viability of generating the $\alpha$-amino radicals from $N$-protected $\alpha$-amino acids via facile visible light-driven single-electron oxidative decarboxylation. Inspired by these contributions, we began our study by exploring the model reaction between $a$-bromoketone $\mathbf{1 a}$ and $N$-phenyl glycine (2a) with our developed metal-free ${ }^{18}$ dicyanopyrazine-derived chromophore (DPZ)19,20 as the photoredox catalyst (Table 1). Initial investigations using Stern-Volmer experiments revealed that the excited DPZ $\left({ }^{\star} \mathrm{DPZ}\right)$ species can facilitate single-electron oxidation of 1a. Upon examining a range of reaction parameters, we observed that the reaction performed in 1,2-dimethoxyethane at $0{ }^{\circ} \mathrm{C}$ for $60 \mathrm{~h}$ in the presence of $0.5 \mathrm{~mol}$ $\%$ DPZ, $10 \mathrm{~mol} \%$ chiral SPINOL-CPA ${ }^{21} \mathbf{C 1}$, and $3 \AA$ molecular sieves affords a desired $\alpha$-aminoalkyl-substitution product $3 \mathbf{a}$ in $79 \%$ yield with $95 \%$ ee (enantiomeric excess) (entry 1). The substituents at the 6,6'-positions of SPINOL affected the enantioselectivity, and as an evidence, catalysts $\mathbf{C 2 - C 4}$ showed different enantioselectivities for the formation of 3a (entries 2-4). Catalyst BINOL-CPA ${ }^{22-24}$ C5 gave $3 a$ with $45 \%$ ee (entry 5), which confirmed the significant effect of the chiral backbone of the catalyst on the enantioselectivity. The reaction was also examined using L-amino acid-based urea-tertiary amine bifunctional catalyst ${ }^{20} \mathbf{C 6}$, but the yield deteriorated and the reaction was not enantioselective (entry 6). In the absence of the chiral catalyst C1, 3a was formed as an achiral mixture in only $30 \%$ of yield ( $>95 \%$ conversion of 1a, entry 7 ). In both reactions (entries $6-7)$, the reductive debrominative protonation of 1 a became a primary transformation, given that ethyl phenyl ketone (4) was obtained as the major product. The reaction conducted in the absence of DPZ provided 3a in only $20 \%$ of yield with $94 \%$ ee ( $23 \%$ conversion of $1 \mathbf{1 a}$, entry 8 ). These results suggested that the chiral catalyst is crucial for both the chemoselectivity and enantioselectivity, and the photocatalyst is necessary for the reactivity ${ }^{25}$. Control experiments confirmed that visible light is necessary for the transformation (entry 9).

Substrate scope of secondary $\boldsymbol{\alpha}$-bromoketones. To examine the scope of this radical-based enantioconvergent substitution reaction, optimal conditions were evaluated with a wide range of $\mathrm{N}$ aryl amino acids and racemic secondary $\alpha$-bromoketones for the synthesis of $\beta^{2}$-amino ketones (Fig. 2). For the couplings of 1a with $N$-aryl glycines $\mathbf{2 a - f}$, which feature electron-withdrawing or electron-donating substituents on the aryl ring, products 3a-f were obtained in $69-80 \%$ yields with $94-95 \%$ ees. As for the scope of electrophiles, various secondary a-bromoketones with a variety of combinations of substituents (i.e., aryl, alkyl, and benzyl) at the 1 - and 2-positions were compatible with the reaction conditions and provided the corresponding $\beta^{2}$-amino ketones $(3 \mathbf{g}-\mathbf{w})$ in $55-86 \%$ yields with $86-95 \%$ ees. Notably, the free hydroxyl group on the aromatic ring did not interfere with the reaction (product $\mathbf{3 m})$. To improve the enantioselectivity, catalyst $\mathbf{C 2}$ was used to 


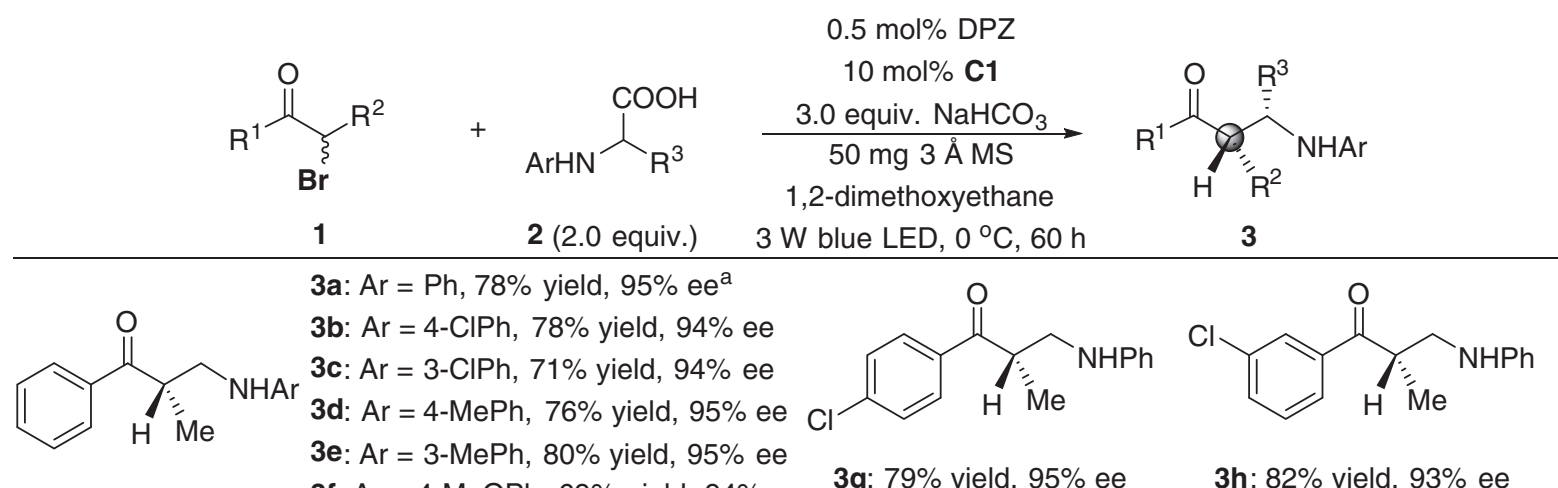<smiles>Cc1ccc(C(=O)[C@H](C)CNc2ccccc2)cc1</smiles>

3i: $86 \%$ yield, $94 \%$ ee<smiles>C[C@H](CNc1ccccc1)C(=O)c1ccc(O)cc1</smiles>

3m: $68 \%$ yield, $88 \%$ ee (at $25^{\circ} \mathrm{C}$ )<smiles>Cc1cccc(C(=O)[C@H](C)CNc2ccccc2)c1</smiles>

3j: $76 \%$ yield, $95 \%$ ee<smiles>C[C@@H](CNc1ccccc1)C(=O)c1cccs1</smiles>

3n: $60 \%$ yield, $86 \%$ ee<smiles>C/C=C\C=C/CN(Cc1ccc(C)cc1)[C@H](Cc1ccccc1)C(=O)c1ccc(C)cc1</smiles>

3q: $73 \%$ yield, $90 \%$ ee<smiles>CC(=O)[C@H](CNc1ccccc1)c1ccccc1</smiles>

3u: $65 \%$ yield, $90 \%$ ee (at $-20^{\circ} \mathrm{C}$ )<smiles>[CH][P+]([O-])(NC[C@@H](Cc1cccc(OC)c1)C(=O)c1ccccc1)C(=O)c1cccc(OC)c1</smiles>

$3 r$ : $60 \%$ yield, $93 \%$ ee<smiles>CC(C)(C)C(=O)[C@H](CNc1ccccc1)c1ccccc1</smiles>

$3 v$ : $55 \%$ yield, $88 \% \mathrm{ee}^{\mathrm{b}}$<smiles>CC[C@H](CNc1ccccc1)C(=O)c1ccc(OC(C)(C)C)cc1</smiles>

3o: $68 \%$ yield, $90 \%$ ee<smiles>O=C(c1ccccc1)[C@H](CNc1ccccc1)c1ccccc1</smiles>

3s: $55 \%$ yield, $87 \%$ ee ${ }^{b}$<smiles>CC[C@H](CNc1ccccc1)C(=O)C(C)(C)C</smiles><smiles>COc1ccccc1NC(C)[C@H](C)C(=O)c1ccccc1</smiles>

3w: $61 \%$ yield, $93 \%$ ee (at $-20^{\circ} \mathrm{C}$ )<smiles>COc1cccc(C(=O)[C@H](C)CNc2ccccc2)c1</smiles>

3I: $68 \%$ yield, $94 \%$ ee<smiles>O=C(c1ccccc1)[C@H](CNc1ccccc1)Cc1ccccc1</smiles>

3p: $67 \%$ yield, $94 \%$ ee<smiles>O=C(c1ccc(Cl)cc1)[C@H](CNc1ccccc1)c1ccc(Cl)cc1</smiles>

3t: $61 \%$ yield, $90 \% \mathrm{ee}^{\mathrm{b}}$

\section{3x: $50 \%$ yield} $96 \%$ ee, $>20: 1 d r$<smiles>COc1ccccc1N[C@H](C)[C@H](C)C(=O)c1ccc(Br)cc1</smiles>

3y: $46 \%$ yield $96 \%$ ee, $>20: 1 d r$

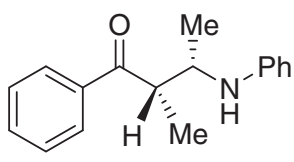

3z: $51 \%$ yield $97 \%$ ee, $>20: 1 d r$ 2c: $\mathrm{Ar}=3-\mathrm{CIPh}, \mathrm{R}^{3}=\mathrm{H}$
2d: $\mathrm{Ar}=4-\mathrm{MePh}, \mathrm{R}^{3}=\mathrm{H}$
2e: $\mathrm{Ar}=3-\mathrm{MePh}, \mathrm{R}^{3}=\mathrm{H}$
2f: $\mathrm{Ar}=4-\mathrm{MeOPh}, \mathrm{R}^{3}=\mathrm{H}$
2g: $\mathrm{Ar}=4-\mathrm{MeOPh}, \mathrm{R}^{3}=\mathrm{Me}$ 2h: $\mathrm{Ar}=\mathrm{Ph}, \mathrm{R}^{3}=\mathrm{Me}$

Fig. 2 Substrate scope of $N$-aryl amino acids and secondary $\alpha$-bromoketones. Reactions were performed with $\mathbf{1}(0.1 \mathrm{mmol}), 2(0.2 \mathrm{mmol}), \mathrm{DPZ}\left(0.5 \times 10^{-3}\right.$ $\mathrm{mmol}), \mathbf{C 1}(0.01 \mathrm{mmol}), \mathrm{NaHCO}_{3}(0.3 \mathrm{mmol})$, and $3 \AA \mathrm{MS}(50 \mathrm{mg})$ in 1,2-dimethoxyethane $(1.5 \mathrm{~mL})$ at $0{ }^{\circ} \mathrm{C}$. Yields were determined from the isolated material after chromatographic purification. Enantiomeric excesses were determined by HPLC analysis on a chiral stationary phase. ${ }^{a}$ On a 1.0 mmol scale and $60 \mathrm{~h}$, yield of $\mathbf{3 a}=75 \%$ and ee $=94 \%$ ( $2 \times 3 \mathrm{~W}$ blue LED). ${ }^{b}$ Catalyst $\mathbf{C 2}$ was used instead of $\mathbf{C 1}$ 


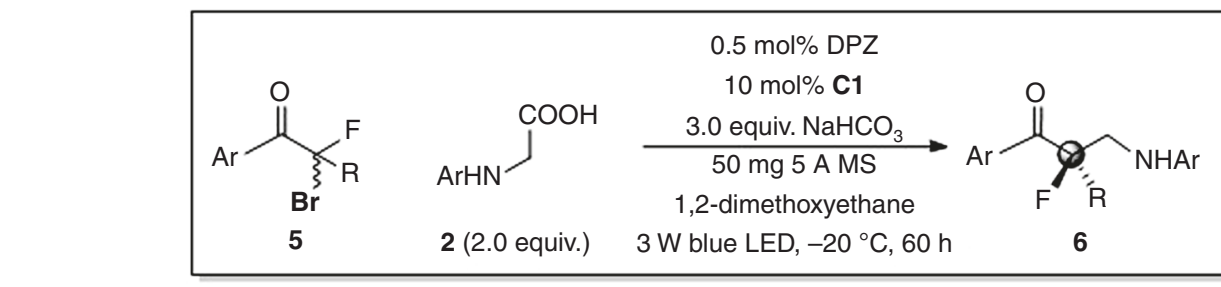<smiles>[Y6]C(F)(CNc1ccccc1)C(=O)c1ccccc1</smiles>

6a: $75 \%$ yield, $90 \%$ ee<smiles>Cc1ccc(C(=O)[C@](C)(F)CNc2ccccc2)cc1</smiles>

6e: $70 \%$ yield, $90 \%$ ee<smiles>COc1cccc(C(=O)[C@](C)(F)CNc2ccccc2)c1</smiles>

6i: $66 \%$ yield, $90 \%$ ee<smiles>CC(F)(CNc1ccccc1)C(=O)c1ccc(F)cc1</smiles>

6b: $65 \%$ yield, $86 \%$ ee<smiles>CCc1ccc(C(=O)[C@](C)(F)CNc2ccccc2)cc1</smiles>

6f: $70 \%$ yield, $90 \%$ ee

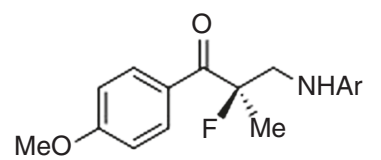

6j: $\mathrm{Ar}=4-\mathrm{MeOPh}$ $68 \%$ yield, $87 \%$ ee $6 \mathrm{k}: \mathrm{Ar}=4-\mathrm{BrPh}$ $80 \%$ yield, $88 \%(94 \%) \mathrm{ee}^{\mathrm{a}}$ (from $2 \mathrm{~h}$ )<smiles>O=C([C](F)CNc1ccccc1)c1ccc(Cl)cc1</smiles>

6c: $60 \%$ yield, $86 \%$ ee<smiles>Cc1cccc(C(=O)[C@](C)(F)CNc2ccccc2)c1</smiles>

6g: $68 \%$ yield, $86 \%$ ee<smiles>[Y6]C(F)(CNc1ccccc1)C(=O)c1ccc(Br)cc1</smiles>

6d: $69 \%$ yield, $86 \%$ ee<smiles>COc1ccc(C(=O)C(C)(F)CNc2ccccc2)cc1</smiles>

6h: $70 \%$ yield, $90 \%$ ee<smiles>CC[C@@](F)(CNc1ccccc1)C(=O)c1ccccc1</smiles><smiles>C=CC[C@](F)(CNc1ccccc1)C(=O)c1ccccc1</smiles>

6I: $65 \%$ yield, $80 \%$ ee

6m: $65 \%$ yield, $78 \%$ ee

Fig. 3 Substrate scope of tertiary $\alpha$-bromo- $\alpha$-fluoroketones with $\mathrm{N}$-aryl glycines. Reactions were performed with $\mathbf{5}$ (0.1 mmol), 2 (0.2 mmol), DPZ $\left(0.5 \times 10^{-3} \mathrm{mmol}\right), \mathbf{C 1}(0.01 \mathrm{mmol}), \mathrm{NaHCO}_{3}(0.3 \mathrm{mmol})$, and $5 \AA \mathrm{MS}(50 \mathrm{mg})$ in 1,2-dimethoxyethane $(1.5 \mathrm{~mL})$ at $-20^{\circ} \mathrm{C}$. Yields were determined from the isolated material after chromatographic purification. Enantiomeric excesses were determined by HPLC analysis on a chiral stationary phase. ${ }^{a} \mathrm{The}$ ee value in parenthesis was obtained after recrystallization. ${ }^{b}$ Catalyst $\mathbf{C 3}(20 \mathrm{~mol} \%)$ was used instead of $\mathbf{C} 1$ and $T=-45^{\circ} \mathrm{C}$

generate products $3 \mathbf{s}, \mathbf{t}$ and $\mathbf{3 v}$. The reaction to access $\mathbf{3 a}$ was attempted on a $1.0 \mathrm{mmol}$ scale, but under an irradiation by two 3 W blue LEDs, and the similar yield (75\%) and enantioselectivity (94\% ee) were observed. Reactions of $\mathbf{1}$ with $\mathrm{N}-\mathrm{MeOPh}(\mathbf{2 g})$ and $\mathrm{N}$-Ph (2h) alanines were also carried out, and adducts $3 \mathbf{x}-\mathbf{z}$ containing two adjacent tertiary carbon stereocenters were obtained in $46-51 \%$ yields with $96-97 \%$ ees and $>20: 1$ drs. A slightly decreased yield can be attributed to the decreased chemoselectivity of the coupling reactions. When examining other $a-$ substituted $N$-aryl amino acids, this undesirable side reaction became dominant, and the reductive debrominative protonation product of 1 was observed almost exclusively.

Substrate scope of $\boldsymbol{\alpha}$-bromo- $\boldsymbol{\alpha}$-fluoroketones. Motivated by the potential applications of organofluorine compounds in a variety of scientific disciplines 26,27 , the scope of $a$-bromo- $\alpha$ fluoroketones 5 was examined next (Fig. 3). Under the established reaction conditions, but using $5 \AA \mathrm{MS}$ as an additive and at $-20^{\circ} \mathrm{C}$, chiral $\beta$-fluoro- $\beta$-methyl amino ketones $\mathbf{6 a - k}$ were prepared in $60-80 \%$ yields with $84-94 \%$ ees. When the $\alpha$-substituent of 5 was ethyl and allyl, the enantioselectivities were lower. However, switching from catalyst $\mathbf{C 1}$ to $\mathbf{C 3}(20 \mathrm{~mol} \%)$ and performing the reaction at a lower temperature $\left(-45^{\circ} \mathrm{C}\right)$ allowed products $\mathbf{6 1 - \mathbf { m }}$ to be generated with good enantioselectivity.

Substrate scope of tertiary $\boldsymbol{\alpha}$-bromoketones. Encouraged by these results, we extended the generality of the reaction with regard to racemic tertiary $\alpha$-bromoketones 7 to address the challenge of forming full-carbon quaternary stereocenters (Fig. 4). Although the tertiary carbon radicals feature higher steric hindrance, the reactions proceeded smoothly with similar reactivity and chemoselectivity, and afforded $\beta^{2,2}$ amino ketones $8 \mathbf{a}-\mathbf{i}$ in $60-70 \%$ yields. To achieve the best enantioselectivity, catalyst $\mathbf{C} 3$ was used for the preparation of $\mathbf{8 a - e}(82-92 \%$ ee), C2 was used for $\mathbf{8 f}-\mathbf{h}$ (84-90\% ee), and C4 was used for $8 \mathbf{i}$ ( $84 \%$ ee). Other chiral $\beta^{2,2}$-amino ketones could be obtained with high enantioselectivity by tuning the $6,6^{\prime}$-substituents of the catalyst.

Synthetic applications. Enantiomerically pure $\beta^{2-}$ and $\beta^{2,2_{-}}$ amino ketones are prevalent in biologically active compounds ${ }^{28}$ and are direct precursors ${ }^{29-32}$ to a number of important chiral structural motifs such as $\beta^{2}$ - and $\beta^{2,2}$-amino acids, derivatives for peptide synthesis 30,31 , and fluorohydrins ${ }^{32}$. For example, the treatment of $\beta^{2,2}$-amino ketone $\mathbf{6 j}$ with $N, N^{\prime}, N^{\prime \prime}$ trichloroisocyanuric acid (9), followed by $p$-toluenesulfonyl chloride could replace the para-methoxyphenyl (PMB) $N$-protective group with a tosyl (Ts) group (Fig. 5). The resulting $\beta^{2,2}$ amino ketone $\mathbf{1 0}$ was readily converted to fluorine-containing chiral ester 11 by a Baeyer-Villiger rearrangement with $m \mathrm{CPBA}$. Meanwhile, the reduction of $\mathbf{6 j}$ using $\mathrm{TiCl}_{4}$ and $\mathrm{BH}_{3} \cdot \mathrm{Me}_{2} \mathrm{~S}$ in $\mathrm{THF}$ at $-78^{\circ} \mathrm{C}$ furnished fluorohydrin 12 with perfect diastereoselectivity and without erosion of the ee. 


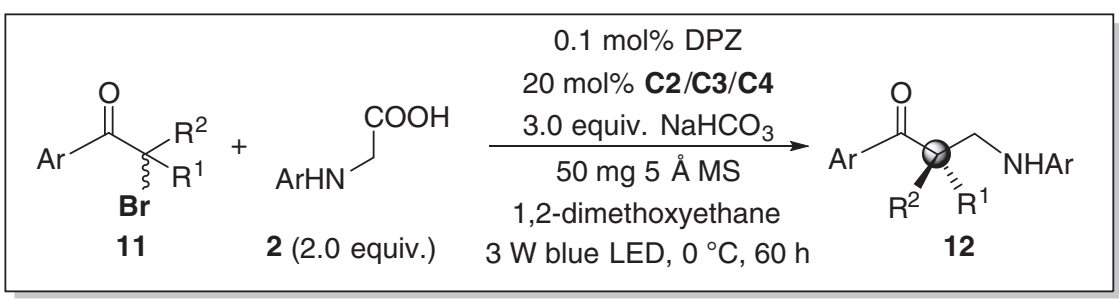<smiles>CCNC[C@](C)(C(=O)c1ccccc1)c1ccccc1</smiles>

12a $: \mathrm{Ar}=\mathrm{Ph}$ $69 \%$ yield, $90 \%$ ee 12b: $\mathrm{Ar}=4-\mathrm{MeOPh}$ $70 \%$ yield, $87 \%$ ee (with C3)<smiles>O=C(c1ccccc1)C(CNc1ccccc1)(c1ccccc1)c1ccccc1</smiles>

12f: $65 \%$ yield, $90 \%$ ee (with C2)<smiles>COc1ccc(C(=O)[C@](C)(CNc2ccccc2)c2ccccc2)cc1</smiles>

12c : $66 \%$ yield, $92 \%$ ee (with C3)

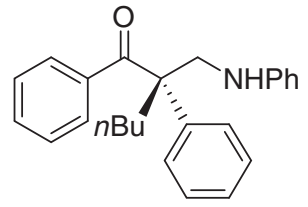

12g: $61 \%$ yield, $85 \%$ ee (with C2)

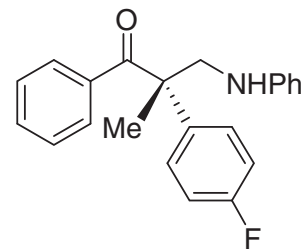

12d: $68 \%$ yield, $82 \%$ ee (with C3)<smiles>CC(C)C[C@@](CNc1ccccc1)(C(=O)c1ccccc1)c1ccccc1</smiles>

12h: $60 \%$ yield, $86 \%$ ee (with C2)

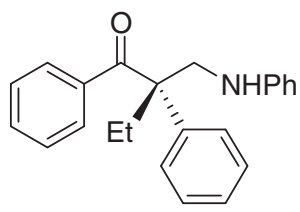

12e: $70 \%$ yield, $92 \%$ ee (with C3)<smiles>CC(C)[C@](C)(CNc1ccccc1)C(=O)c1ccccc1</smiles>

12i: $63 \%$ yield, $84 \%$ ee (with C4)

Fig. 4 Substrate scope of tertiary $\alpha$-bromoketones. Reactions were performed with $\mathbf{7}(0.1 \mathrm{mmol}), \mathbf{2}(0.2 \mathrm{mmol}), \mathrm{DPZ}\left(0.1 \times 10^{-3} \mathrm{mmol}\right), \mathbf{C 2} / \mathbf{C 3} / \mathbf{C 4}(0.02$ $\mathrm{mmol}), \mathrm{NaHCO}_{3}(0.3 \mathrm{mmol})$, and $5 \AA \mathrm{MS}(50 \mathrm{mg})$ in 1,2-dimethoxyethane $(1.5 \mathrm{~mL})$ at $0{ }^{\circ} \mathrm{C}$. Yields were determined based on the isolated material after chromatographic purification. Enantiomeric excesses were determined by HPLC analysis on a chiral stationary phase

Mechanistic studies. Although the above results and previous reports $18,33,34$ are consistent with a redox-neutral radical process triggered by the reductive quenching of $\mathrm{DPZ}^{\star}$, as depicted in Fig. 1c, control experiments were performed to further probe the reaction mechanism (Fig. 6). A radical-clock study using ciscyclopropyl-substituted $\alpha$-bromoketones 13 and 2 a was conducted first (Fig. 6a). $\beta^{2}$-amino ketone 14 was obtained in $70 \%$ yield, and no ring-opened product was observed due to the maintained configuration of the cyclopropyl moiety. This result confirmed that the radical intermediates generated from the SET reductive debromination of $a$-bromoketones are very active and quickly couple with the $\alpha$-amino radicals. The high reactivity of these alkyl radicals is consistent with the result of the reaction between $\mathbf{1 a}$ and $N$-phenyl alanine (2h) in the presence of the radical scavenger TEMPO (1.5 equiv.), where product 15 was obtained in 55\% yield via coupling with TEMPO (Fig. 6b). Notably, this reaction also generated products 4 and 4 -amino tetrahydroquinoline $\mathbf{1 6}$ in $38 \%$ and $20 \%$ yields, respectively, but $\beta^{2}$-amino ketone $\mathbf{3 z}$ was not observed. Product $\mathbf{1 6}$ is likely generated from the Povarov reaction between the imine formed by two SET oxidations of $\mathbf{2 i}$ and an enamine (the tautomer of the imine). Hence, the second reductive protonation of the alkyl radical must be fast and the substitution products should be formed by a radical cross-coupling reaction as the major operative process and not by a Mannich-type reaction of the a-ketone anion with an imine. Such an ionic pathway and a possible radical addition process could be further excluded by the control experiment shown in Fig. $6 c$, in which the reaction of $\alpha$ bromoketone 7a with $N$-phenyl glycine 2a and $N-\mathrm{MeOPh}$ imine $\mathbf{1 7}$ derived from formaldehyde worked slightly sluggish, but very clean, only affording $\mathbf{8 b}$ in $42 \%$ yield with $22 \%$ ee after $48 \mathrm{~h}$ and without $8 \mathbf{a}$ being detected. Of note, the transformation of $7 \mathbf{a}$ with $\mathrm{N}-\mathrm{MeOPh}$ glycine $\mathbf{2 f}$ under the reaction conditions furnished $\mathbf{8 b}$ with $87 \%$ ee (Fig. 4). The different enantioselective results suggest two distinct approaches to access $\mathbf{8 b}$ in both reactions. Furthermore, while 8a was not obtained, imine $\mathbf{1 8}$ through two singleelectron oxidations of $\mathbf{2 a}$ was not observed yet, which also eliminated the possibility of $\beta^{2}$ - and $\beta^{2,2}$-amino ketones obtained from the transformations with imines in our reaction system. For higher concentration of product $\mathbf{8 b}$ from imine $\mathbf{1 7}$, it should be obtained from a Mannich-type radical addition than the $\alpha$-amino radical generated from 2a. In this process, the excellent reactivity that has been described by Knowles and co-workers ${ }^{28}$ could be demonstrated by the result that no ketone $\mathbf{1 9}$ as the debrominative protonation product was detected. It is also worth mentioning that no reaction was detected when three kinds of the parent ketones with imine $\mathbf{1 7}$ were under the corresponding standard reaction conditions.

Chiral phosphoric acid catalysts were shown to provide higher selectivity for the radical coupling reaction over the reductive debrominative protonation (entries 1 and 7, Table 1). According to the persistent radical effect ${ }^{35}$, it is plausible that phosphoric acid would act as a bifunctional $\mathrm{H}$-bonding catalyst ${ }^{29}$ to stabilize the electrophilic alkyl radical species and activate the nucleophilic $\alpha$-amino radical variant, thus facilitating the selective $\mathrm{C}-\mathrm{C}$ bond formation, but not the SET-redox reaction. The decreased yield with $N$-phenyl- $N$-methyl glycine as a starting material ( $45 \%$ yield, see Supplementary Table 3 ) and the ${ }^{13} \mathrm{C}$ NMR analysis between substrate and catalyst (Supplementary Note 2) could be recognized as circumstantial evidences to demonstrate this hypothesized activation approach. This H-bonding effect offers another method of controlling the enantioselectivity of the formation of chiral substitution products. Additionally, a linear relationship was found between the ee of product $\mathbf{3 t}$ and the ee of acid catalyst $\mathbf{C 2}$ (Fig. 6d). This result suggests only a single molecule of chiral phosphate was involved in the crucial $\mathrm{C}-\mathrm{C}$ bond-forming step. More investigations were continuously being conducted in our laboratory to make an accurate understanding of the mechanism. 


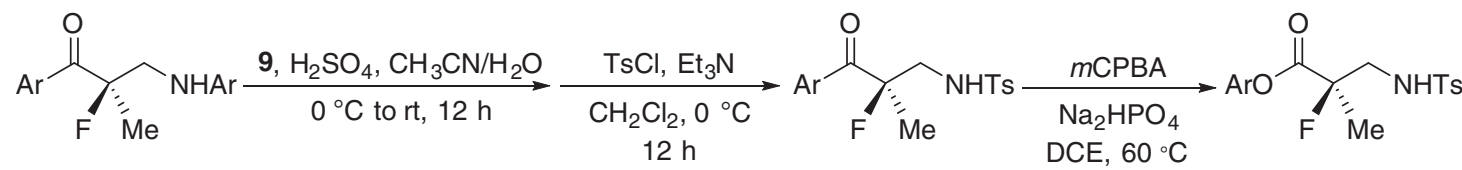

6j: $\mathrm{Ar}=4-\mathrm{MeOPh}$

$87 \%$ ee
$72 \%$ yield of two steps

$87 \%$ ee
$24 \mathrm{~h}$

11

$70 \%$ yield

$87 \%$ ee

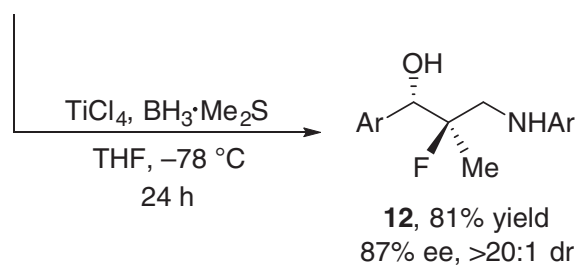

Fig. 5 Synthetic utilities. The synthesis of $\beta^{2}$-fluoro- $\beta^{2}$-substituted amino ester $\mathbf{1 1}$ and fluorohydrin $\mathbf{1 2}$ from chiral $\beta$-fluoro- $\beta$-methyl amino ketone $\mathbf{6 j}$

a<smiles></smiles>

13

b
When using 3.0 equiv. TEMPO: NO REACTION

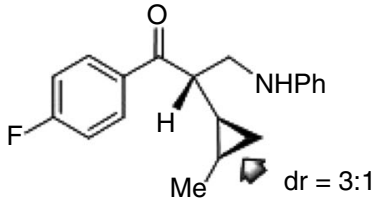

14: $70 \%$ yield<smiles>CC(Br)C(=O)c1ccccc1</smiles>

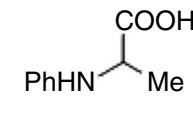
as Table 2<smiles>[Y4][C@H](Nc1ccccc1)C(=O)c1ccccc1</smiles><smiles>CCC(=O)c1ccccc1</smiles>

1a

2h (2.0 equiv.)

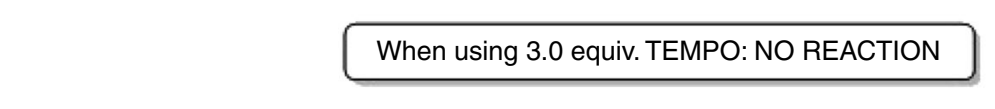

$3 z$ (not observed)

$4(38 \%$ yield)<smiles>CC(ON1C(C)(C)CCCC1(C)C)C(=O)c1ccccc1</smiles><smiles>CC1CC(Nc2ccccc2)c2ccccc2N1</smiles>

15 (55\% yield)

$16(20 \%$ yield $)$

C

c<smiles>C[C@](Br)(C(=O)c1ccccc1)C(Br)(c1ccccc1)c1ccccc1</smiles><smiles>C=Nc1ccc(CCCCOC(C)C)cc1</smiles>

$0.1 \mathrm{~mol} \% \mathrm{DPZ}$

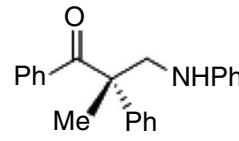

$\overbrace{\mathrm{Me}}^{\mathrm{O}} \mathrm{NHAr}$

8b: $\mathrm{Ar}=4-\mathrm{MeOPH}$

$42 \%$ yield, $22 \%$ ee

$50 \mathrm{mg} 5 \AA \mathrm{MS}$

$\rightarrow \mathbf{8 a}$ (not observed)<smiles>CC(C(=O)c1ccccc1)c1ccccc1</smiles>

18 (not observed)

19 (not observed)
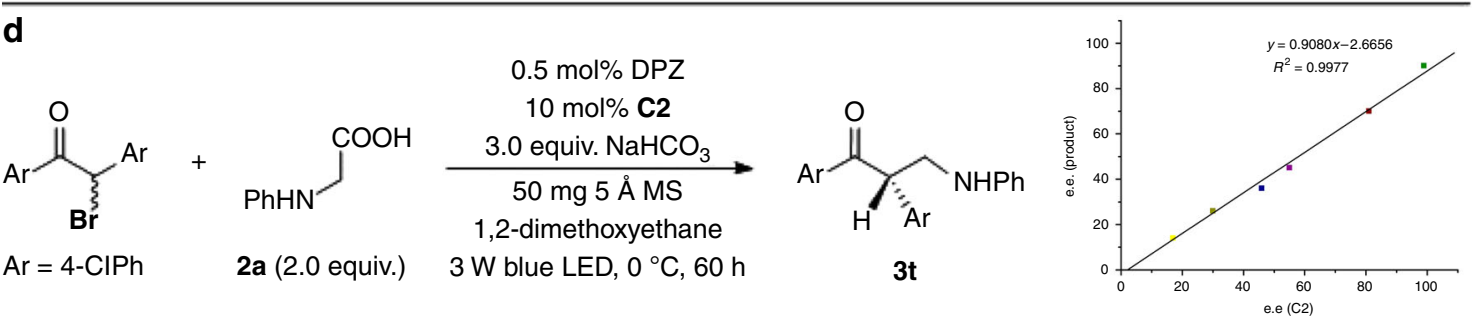

Fig. 6 Experimental studies to elucidate the mechanism. a Radical-clock examination. $\mathbf{b}$ Investigation on the effect of TEMPO. c The reaction of bromoketone $\mathbf{7 a}$ with $\mathrm{N}$-phenyl glycine $\mathbf{2} \mathbf{a}$ and imine $\mathbf{1 7}$. $\mathbf{d}$ The study on the relationship between ee of the CPA C2 and ee of the product $\mathbf{3 t}$

\section{Discussion}

In summary, we have developed a catalytic asymmetric photoredox radical-coupling method as a versatile strategy for the enantioconvergent substitution of alkyl halides. Alkyl radicals generated from the visible light-driven photoreductive dehalogenation of simple alkyl halides undergoing diverse radical-based transformations have been well-studied $33,34,36,37$. The high enantioselectivity in conjunction with broad substrate scope for $\mathrm{C}_{\mathrm{sp} 3}-\mathrm{C}_{\mathrm{sp} 3}$ bond 
formation, especially the success in the construction of challenging fluoro-hetero-quaternary and full-carbon quaternary stereocenters, provides a crucial foundation for the pursuit of other valuable enantioconvergent substitution transformations of alkyl halides with readily available and bench-stable organic molecules.

\section{Methods}

General information. For the NMR spectra of compounds in this manuscript, see Supplementary Figs. 1-80. For the HPLC spectra of compounds in this manuscript, see Supplementary Figs. 81-141. For details of optimization of reaction conditions, see Supplementary Tables 1-3. For the synthesis of substrates 13, 17, and 22, see Supplementary Note 1. For details of mechanistic studies, see Supplementary Note 2. For details of synthetic applications, see Supplementary Note 3. For the determination of absolute configuration of products, sees Supplementary Note 4. For general information, general experimental procedure, and analytic data of compounds synthesized, see Supplementary Methods.

Preparation of 3. A total of $35.4 \mu \mathrm{L}(0.0005 \mathrm{mmol}, 0.005$ equiv. $)$ of $\mathrm{DPZ}$ solution ( $1.0 \mathrm{mg}$ of DPZ in $200 \mu \mathrm{L}$ of toluene) was added into a $10-\mathrm{mL}$ Schlenk tube and then solvent was removed in vacuo. Subsequently, 1 ( $0.1 \mathrm{mmol}, 1.0$ equiv.), $2(0.2$ mmol, 2.0 equiv.), $\mathbf{C 1}$ ( $0.01 \mathrm{mmol}, 0.1$ equiv.) for $\mathbf{3 a}-\mathbf{r}, \mathbf{u}, \mathbf{w}, \mathbf{x}, \mathbf{y}$ and $\mathbf{z}$ or $\mathbf{C 2}(0.01$ mmol, 0.1 equiv.) for $3 \mathbf{s}, \mathbf{t}$, and $\mathbf{v}, 3 \AA$ molecular sieves $(50.0 \mathrm{mg})$, and $\mathrm{NaHCO}_{3}$ ( $25.2 \mathrm{mg}, 3.0$ equiv.) in 1,2-dimethoxyethane $(1.5 \mathrm{~mL})$ were sequentially added and then degassed three times by the freeze-pump-thaw method. The reaction mixture was stirred under an argon atmosphere at $0^{\circ} \mathrm{C}$ (the temperature was maintained in an incubator) for $30 \mathrm{~min}$ without light, and then irradiated by a $3 \mathrm{~W}$ blue LED ( $\lambda$ $=450-455 \mathrm{~nm}$ ) from a $3.0 \mathrm{~cm}$ distance for another $60 \mathrm{~h}$. The reaction mixture was directly loaded onto a short silica gel column, followed by gradient elution with petroleum ether/ethyl acetate (200/1-20/1 ratio). Removing the solvent in vacuo afforded products $\mathbf{3 a}-\mathbf{z}$.

Preparation of 6. A total of $35.4 \mu \mathrm{L}(0.0005 \mathrm{mmol}, 0.005$ equiv. $)$ of DPZ solution ( $1.0 \mathrm{mg}$ of DPZ in $200 \mu \mathrm{L}$ of toluene) was added into a $10-\mathrm{mL}$ Schlenk tube and then the solvent was removed in vacuo. Subsequently, 5 ( $0.1 \mathrm{mmol}, 1.0$ equiv.), 2 (0.2 mmol, 2.0 equiv.), C1 ( $0.01 \mathrm{mmol}, 0.1$ equiv.) for $\mathbf{6 a}-\mathbf{k}$ or $\mathbf{C 3}(0.02 \mathrm{mmol}, 0.2$ equiv.) for $\mathbf{6 l}$ and $\mathbf{m}, 5 \AA$ molecular sieves (50.0 mg), $\mathrm{NaHCO}_{3}(25.2 \mathrm{mg}, 3.0$ equiv.) in 1,2-dimethoxyethane $(1.5 \mathrm{~mL})$ were sequentially added and then degassed three times by the freeze-pump-thaw method. The reaction mixture was stirred under an argon atmosphere at $-20^{\circ} \mathrm{C}$ for $\mathbf{6 a}-\mathbf{k}$ or at $-45^{\circ} \mathrm{C}$ for $\mathbf{6 l}$ and $\mathbf{m}$ (the temperature was maintained in an incubator) for $30 \mathrm{~min}$ without light, and then irradiated by a $3 \mathrm{~W}$ blue $\operatorname{LED}(\lambda=450-455 \mathrm{~nm})$ from a $3.0 \mathrm{~cm}$ distance for another $60 \mathrm{~h}$. The reaction mixture was directly loaded onto a short silica gel column, followed by gradient elution with petroleum ether/ethyl acetate (200/1-20/1 ratio). Removing the solvent in vacuo afforded products $\mathbf{6 a - m}$.

Preparation of 8. A total of $7.1 \mu \mathrm{L}(0.0001 \mathrm{mmol}, 0.001$ equiv. $)$ of DPZ solution ( $1.0 \mathrm{mg}$ of DPZ in $200 \mu \mathrm{L}$ of toluene) was added into a $10-\mathrm{mL}$ Schlenk tube and then solvent was removed in vacuo. Subsequently, 7 ( $0.1 \mathrm{mmol}, 1.0$ equiv.), $2(0.2$ mmol, 2.0 equiv.), C2 ( $0.02 \mathrm{mmol}, 0.2$ equiv.) for $\mathbf{8 f}-\mathbf{h}, \mathbf{C} 3$ ( $0.02 \mathrm{mmol}, 0.2$ equiv.) for $8 \mathbf{a}-\mathbf{e}$, or $\mathbf{C 4}(0.02 \mathrm{mmol}, 0.2$ equiv.) for $\mathbf{8 i}, 5 \AA$ molecular sieves $(50.0 \mathrm{mg})$, $\mathrm{NaHCO}_{3}$ (25.2 mg, 3.0 equiv.) in 1,2-dimethoxyethane $(1.5 \mathrm{~mL})$ were sequentially added and then degassed three times by the freeze-pump-thaw method. The reaction mixture was stirred under an argon atmosphere at $0{ }^{\circ} \mathrm{C}$ (the temperature was maintained in an incubator) for $30 \mathrm{~min}$ without light, and then irradiated by a $3 \mathrm{~W}$ blue $\operatorname{LED}(\lambda=450-455 \mathrm{~nm})$ from a $3.0 \mathrm{~cm}$ distance for another $60 \mathrm{~h}$. The reaction mixture was directly loaded onto a short silica gel column, followed by gradient elution with petroleum ether/ethyl acetate (200/1-20/1 ratio). Removing the solvent in vacuo afforded products $8 \mathbf{8}-\mathbf{i}$.

Data availability. The X-ray crystallographic coordinates for structures that support the findings of this study have been deposited at the Cambridge Crystallographic Data Centre (CCDC) with the accession code CCDC 1587114 (12), 1589705 (25), and 1814679 (26). The authors declare that all other data supporting the findings of this study are available within the article and Supplementary Information files, and also are available from the corresponding author upon reasonable request.

Received: 15 January 2018 Accepted: 29 May 2018

Published online: 22 June 2018

\section{References}

1. Hartshorn, S. R. Aliphatic Nucleophilic Substitution (Cambridge University Press, London, 1973).

2. Anslyn, E. V. \& Dougherty, D. A. (eds) in Modern Physical Organic Chemistry Ch 11 (University Science Books, Sausalito, CA, 2006).
3. Reisman, S. E., Doyle, A. G. \& Jacobsen, E. N. Enantioselective thioureacatalyzed additions to oxocarbenium ions. J. Am. Chem. Soc. 130, 7198-7199 (2008).

4. Ma, S., Han, X., Krishnan, S., Virgil, S. C. \& Stoltz, B. M. Catalytic enantioselective stereoablative alkylation of 3-halooxindoles: facile access to oxindoles with C3 all-carbon quaternary stereocenters. Angew. Chem. Int. Ed. 48, 8037-8041 (2009).

5. Kennedy, C. R. et al. Mechanism-guided development of a highly active bisthiourea catalyst for anion-abstraction catalysis. J. Am. Chem. Soc. 138, 13525-13528 (2016)

6. Fischer, C. \& Fu, G. C. Asymmetric nickel-catalyzed Negishi cross-couplings of secondary a-bromo amides with organozinc reagents. J. Am. Chem. Soc. 127, 4594-4595 (2005).

7. Schley, N. D. \& Fu, G. C. Nickel-catalyzed Negishi arylations of propargylic bromides: a mechanistic investigation. J. Am. Chem. Soc. 136, 16588-16593 (2014).

8. Cherney, A. H., Kadunce, N. T. \& Reisman, S. E. Enantioselective and enantiospecific transition-metal-catalyzed cross-coupling reactions of organometallic reagents to construct C-C bonds. Chem. Rev. 115, 9587-9652 (2015).

9. Fu, G. C. Transition-metal catalysis of nucleophilic substitution reactions: a radical alternative to $S_{N} 1$ and $S_{N} 2$ processes. ACS Cent. Sci. 3, 692-700 (2017).

10. Choi, J. \& Fu, G. C. Transition metal-catalyzed alkyl-alkyl bond formation: another dimension in cross-coupling chemistry. Science 356, eaaf7230 (2017).

11. Kainz, Q. M. et al. Asymmetric copper-catalyzed C-N cross-couplings induced by visible light. Science 351, 681-684 (2016)

12. Rajesh, C. S., Thanulingam, T. L. \& Das, S. Photoelectron transfer induced decarboxylation of substituted carboxylic acids across a liquid/liquid interface. Tetrahedron 53, 16817-16834 (1997).

13. Chen, L. et al. Amphiphilic methyleneamino synthon through organic dye catalyzed-decarboxylative aminoalkylation. Org. Biomol. Chem. 11, 5922-5925 (2013).

14. Zuo, Z. \& MacMillan, D. W. C. Decarboxylative arylation of $a$-amino acids via photoredox catalysis: a one-step conversion of biomass to drug pharmacophore. J. Am. Chem. Soc. 136, 5257-5260 (2014).

15. Zuo, Z. et al. Enantioselective decarboxylative arylation of $\alpha$-amino acids via the Merger of photoredox and nickel catalysis. J. Am. Chem. Soc. 138, 1832-1835 (2016).

16. Johnston, C. P., Smith, R. T., Allmendinger, S. \& MacMillan, D. W. C. Metallaphotoredox-catalysed $s p^{3}-s p^{3}$ cross-coupling of carboxylic acids with alkyl halides. Nature 536, 322-325 (2016).

17. Millet, A., Lefebvre, Q. \& Rueping, M. Visible-Light photoredox-catalyzed Giese reaction: decarboxylative addition of amino acid derived $\alpha$-amino radicals to electron-deficient olefins. Chem. Eur. J. 22, 13464-13468 (2016).

18. Romero, N. A. \& Nicewicz, D. A. Organic photoredox catalysis. Chem. Rev. 116, 10075-10166 (2016).

19. Wei, G. et al. Enantioselective aerobic oxidative $\mathrm{C}(\mathrm{sp} 3)-\mathrm{H}$ olefination of amines via cooperative photoredox and asymmetric catalysis. ACS Catal. 6, 3708-3712 (2016)

20. Lin, L. et al. Organocatalytic enantioselective protonation for photoreduction of activated ketones and ketimines induced by visible light. Angew. Chem. Int. Ed. 56, 13842-13846 (2017).

21. Čorić, I., Müller, S. \& List, B. Kinetic resolution of homoaldols via catalytic asymmetric transacetalization. J. Am. Chem. Soc. 132, 17370-17373 (2010).

22. Akiyama, T. Stronger Brønsted acids. Chem. Rev. 107, 5744-5758 (2007).

23. Rono, L. J., Yayla, H. G., Wang, D. Y., Armstrong, M. F. \& Knowles, R. R. Enantioselective photoredox catalysis enabled by proton-coupled electron transfer: development of an asymmetric Aza-pinacol cyclization. J. Am. Chem. Soc. 135, 17735-17738 (2013).

24. Proctor, R. S. J., Davis, H. J. \& Phipps, R. J. Catalytic enantioselective Miniscitype addition to heteroarenes. Science 360, 419-422 (2018). Science 360, 419-422 (2018).

25. Arceo, E., Jurberg, I. D., Álvarez-Fernández, A. \& Melchiorre, P. Photochemical activity of a key donor-acceptor complex can drive stereoselective catalytic a-alkylation of aldehydes. Nat. Chem. 5, 750-756 (2013).

26. Liang, Y. \& Fu, G. C. Catalytic asymmetric synthesis of tertiary alkyl fluorides: Negishi cross-couplings of racemic a,a-dihaloketones. J. Am. Chem. Soc. 136, 5520-5524 (2014).

27. Cuadros, S., Dell'Amico, L. \& Melchiorre, P. Forging fluorine-containing quaternary stereocenters by a light-driven organocatalytic aldol desymmetrization process. Angew. Chem. Int. Ed. 56, 11875-11879 (2017)

28. Moffett, R. B. \& Hester, J. B. Central nervous system agents. 4. Analogs of 3 amino-2-phenylpropiophenone. J. Med. Chem. 15, 1243-1247 (1972).

29. Carlier, P. R. et al. Synthesis of a potent wide-spectrum Serotonin-, Norepinephrine-, Dopamine-Reuptake Inhibitor (SNDRI) and a speciesselective dopamine-reuptake inhibitor based on the gamma-amino alcohol functional group. Bioorg. Med. Chem. Lett. 8, 487-492 (1998). 
30. Peddie, V. et al. Fluorinated $\beta^{2}$ - and $\beta^{3}$-amino acids: synthesis and inhibition of $\alpha$-chymotrypsin. Synthesis 2010, 1845-1859 (2010).

31. Yu, J.-S., Noda, H. \& Shibasaki, M. Quaternary $\beta^{2,2}$-amino acids: catalytic asymmetric synthesis and incorporation into peptides by Fmoc-based solidphase peptide synthesis. Angew. Chem. Int. Ed. 57, 818-822 (2018).

32. Haufe, G. Regio- and stereoselective synthesis of vicinal fluorohydrins. J. Fluor. Chem. 125, 875-894 (2004).

33. Narayanam, J. M. R., Tucker, J. W. \& Stephenson, C. R. J. Electron-transfer photoredox catalysis: development of a tin-free reductive dehalogenation reaction. J. Am. Chem. Soc. 131, 8756-8757 (2009).

34. Staveness, D., Bosque, R. \& Stephenson, C. R. J. Free radical chemistry enabled by visible light-induced electron transfer. Acc. Chem. Res. 49, 2295-2306 (2016).

35. Studer, A. The persistent radical effect in organic synthesis. Chem. Eur. J. 7, 1159-1164 (2001).

36. Prier, C. K., Rankic, D. A. \& MacMillan, D. W. C. Visible light photoredox catalysis with transition metal complexes: applications in organic synthesis. Chem. Rev. 113, 5322-5363 (2013).

37. Shaw, M. H., Twilton, J. \& MacMillan, D. W. C. Photoredox catalysis in organic chemistry. J. Org. Chem. 81, 6898-6926 (2016).

38. Nicewicz, D. A. \& MacMillan, D. W. C. Merging photoredox catalysis with organocatalysis: the direct asymmetric alkylation of aldehydes. Science 322, 77-80 (2008).

39. Allen, A. E. \& MacMillan, D. W. C. Synergistic catalysis: a powerful synthetic strategy for new reaction development. Chem. Sci. 3, 633-658 (2012).

40. Brimioulle, R., Lenhart, D., Maturi, M. M. \& Bach, T. Enantioselective catalysis of photochemical reactions. Angew. Chem. Int. Ed. 54, 3872-3890 (2015).

41. Skubi, K. L., Blum, T. R. \& Yoon, T. P. Dual catalysis strategies in photochemical synthesis. Chem. Rev. 116, 10035-10074 (2016).

42. Xie, J., Jin, H. \& Hashimi, A. S. K. The recent achievements of redox-neutral radical C-C cross-coupling enabled by visible-light. Chem. Soc. Rev. 46, 5193-5203 (2017).

43. Chen, W. et al. Building congested ketone: substituted hantzsch ester and nitrile as alkylation reagents in photoredox catalysis. J. Am. Chem. Soc. 138, 12312-12315 (2016).

44. Uraguchi, D., Kinoshita, N., Kizu, T. \& Ooi, T. Synergistic catalysis of ionic Brønsted acid and photosensitizer for a redox neutral asymmetric a-coupling of $\mathrm{N}$-arylaminomethanes with aldimines. J. Am. Chem. Soc. 137, 13768-13771 (2015).

45. Wang, C. et al. Asymmetric radcial-radical cross-coupling through visiblelight-activated iridium catalysis. Angew. Chem. Int. Ed. 55, 685-688 (2016)

46. Ma, J. et al. Visible-light-activated asymmetric $\beta-\mathrm{C}-\mathrm{H}$ functionalization of acceptor-substituted ketones with 1,2-dicarbonyl compounds. J. Am. Chem. Soc. 139, 17245-17248 (2017).

47. Renaud, P. \& Gerster, M. Use of lewis acids in free radical reactions. Angew. Chem. Int. Ed. 37, 2562-2579 (1998)

\section{Acknowledgements}

Grants from NSFC (Nos. 21072044 and 21672052), Innovation Scientists and Technicians Troop Construction Projects of Henan Province, and Henan University are gratefully acknowledged. We also appreciate Miss Xinyi Ye and Prof. Choon-Hong Tan (NTU) for their generous help in the analysis of HRMS data and Mr. Yangyang Shen (ICIQ) for constructive discussions.

\section{Author contributions}

Z.J. conceived and designed the experiments. J.L., M.K., and B.Q. performed the experiments and prepared the Supplementary Information. R.L. and X.Z. helped with isolating the new compounds and analyzing the data. Z.J. wrote the paper. J.L., M.K., and B.Q. contributed equally to this work. All authors discussed the results and commented on the manuscript.

\section{Additional information}

Supplementary Information accompanies this paper at https://doi.org/10.1038/s41467 018-04885-3.

Competing interests: The authors declare no competing interests.

Reprints and permission information is available online at http://npg.nature.com/ reprintsandpermissions/

Publisher's note: Springer Nature remains neutral with regard to jurisdictional claims in published maps and institutional affiliations.

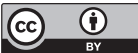

Open Access This article is licensed under a Creative Commons Attribution 4.0 International License, which permits use, sharing, adaptation, distribution and reproduction in any medium or format, as long as you give appropriate credit to the original author(s) and the source, provide a link to the Creative Commons license, and indicate if changes were made. The images or other third party material in this article are included in the article's Creative Commons license, unless indicated otherwise in a credit line to the material. If material is not included in the article's Creative Commons license and your intended use is not permitted by statutory regulation or exceeds the permitted use, you will need to obtain permission directly from the copyright holder. To view a copy of this license, visit http://creativecommons.org/ licenses/by/4.0/.

(c) The Author(s) 2018 